\title{
Acronym Absurdity Constrains Psychological Science
}

\author{
Moin Syed \\ University of Minnesota
}

Version Date: 07/03/20

\section{This essay has not been peer-reviewed and probably never will be}

\section{Author Note}

Alternate titles include, "Old Man Yells at Acronyms," "There is Nothing so Practical as a Good

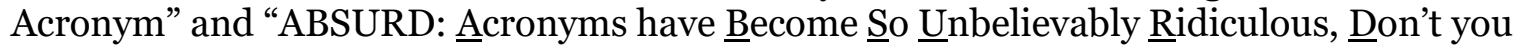
Think?” If you are an Editor and want to publish this. please direct communications to moin@umn.edu. I am waiting.

$* * * * * * * * * * * * * * * * * * * * * * * * * * * * * * * * * * * * *$

Abbrevobabble is an unacceptable outcome because it belays our primary purposeclear exposition of facts and ideas. (Kushlan, 1995, p. 3)

...it is puzzling why scientists would want to erect barriers to the understanding of their studies by publishing articles with abbreviations that make reading difficult for anyone not intimately familiar with that specific field of inquiry. (Brumback, 2009, p. 1477)

Consider this following sentence, which is typical of something that we (social psychologists) might say to a colleague: "Did you read the new PSPB article comparing the accuracy of IATs with the AMP procedure? It is a nice follow up to the JPSP article that came out before SPSP. (Hales et al., 2017)

Ok, look, I am obviously not the first person to rail against abbreviations. The three quotes above all come from articles that highlight how abbreviations can obscure meaning and alienate readers. It is classic scholarly "old man yells at clouds" fodder. But in this essay I will focus on a somewhat different issue, what I will call acronym absurdity, which is how a specific type of abbreviations-acronyms-can have the power to constrain discovery and advancement, thereby shaping science in undesirable ways. My focus in on topics related to psychology, because that is my field, but really the main points are relevant to any field that uses acronyms (i.e., all fields).

First a clarification on terminology. As nicely summarized by Hales et al. (2017) abbreviations represent the broad category of shortening words or a series of words. When that shortening process leads to a series of letters, it can be one of two types: acronyms, which are abbreviations that form new words (e.g., ANOVA), and initialisms, which are letter-based abbreviations that are not understood as words themselves (e.g., SEM). 
My argument here is that there are special problems with acronyms, in particular, although I will touch on some initialisms as well. I call this acronym absurdity because the use of acronyms can sometimes to lead to rather strange outcomes that any reasonable, mildly detached observer can only deem absurd. I focus on two issues here: how catchy acronyms leads to bizarre and limiting choices, and how acronyms can lead to modifications that betray their original intention. My examples are obviously cherry-picked, and there are surely some useful acronyms (see Lang, 2019), but I will continue to assert that the general practice around acronyms is absurd and should largely be abandoned.

\section{Catchy Acronyms Lead to Bizarre Choices}

I will begin with my favorite acronym to shit on: WEIRD. In 2010, Henrich et al. (2010) published a major article in Behavioral and Brain Sciences in which they argued that our psychological knowledge base is limited because it relies heavily on data from individuals coming from Western, Educated, Industrialized, Rich, and Democratic societies. The article was an instant smash hit, and has been cited and discussed heavily ever since. I agree with the general argument, but the paper and its impact have raised a number of problems.

It is rather remarkable, particularly given that the paper was published in a supposed "top-tier" outlet, that the authors do not describe how they identified these five dimensions as constituting the focal set. Are we to believe that five core dimensions just happened to spell WEIRD and that is coincidental with the fact that their primary argument was that studies that rely on samples from WEIRD societies are, in fact, weird in relation to the rest of the world? Of course not. Clearly WEIRD is a backronym, which is fine, except that it should not be taken to have any scientific value. Moreover, it is important to attend to what is being omitted. As we stated in Syed and Kathawalla (2020), "WEIRD is almost too good, which also means it is also almost certainly leaving out other important facets of diversity that should be giving equal attention. WWEIRD (Harden, 2018), with the extra W for White, does not have the same cachet, nor does MWEIRD ("majority") or WEIRDER ("ethnic and racial" majorities). As usual, there is simply no space for ethnic/racial minorities."

Ok, but I am not here to rehash the same arguments. The absurdity goes even deeper. Rather than being a useful thought exercise to bring attention to limited samples, the WEIRD idea has now been extended to create a quantitative index (Muthukrishna et al., 2020). One of the critical commentaries on the Henrich et al. (2010) article argued that the focus should not be on WEIRD, but on WRONG-- When Researchers Overlook uNderlying Genotypes (Gaertner et al., 2010). A recent article suggested that animal behavior research has relied on limited samples, and thus researchers should Beware of STRANGE- Social background; Trappability and self-selection; Rearing history; Acclimation and habituation; Natural changes in responsiveness; Genetic make-up; and Experience. Sticking with the animal theme, I think it is safe to say that we have officially jumped the shark (more on sharks, er, SHARKing later).

If you want to talk about weird acronyms, have you kept up with the ACEs saga? ACEs$\underline{\text { Adverse }}$ Childhood Experiences-were first discussed in Felitti et al. (1998), and rather than attempting to provide a useful acronym for the field they were simply describing the name of their study. Nevertheless, the acronym took off and has seemingly become synonymous with early childhood adversity. However, ACEs is clearly limited. The ACEs scale that is most widely used consist of 10 items that cover emotional, physical, and verbal abuse; emotional and physical neglect; parental separation or divorce; and exposure to domestic violence and household substance abuse, mental illness, and incarceration (Felitti et al., 1998). All very important experiences to understand, but as many have pointed out, far from a complete set 
(e.g., Cronholm et al., 2015) nor can all of these experiences be treated equally (Negriff, 2020). Even some of the original ACEs authors think researchers and practitioners all need to chill on how widely they are applying the concept (Anda et al., 2020).

Once again, however, the absurdity goes much deeper. Any discussion of adversity must also take into account individual's strengths and assets in order to understand resilience (Masten, 2007). So, not to be undone by the ACEs crowd, we now have Benevolent Childhood Experiences (BCEs, pronounced "bee-ses"; Narayan et al., 2018) and Positive Childhood Experiences (PCEs, pronounced "pee-ses"; Bethell et al., 2019). Best I can tell there is no conceptual different between the two, and both brief measures focus heavily on social support. But remember, we are in the land of the absurd, so we are not out of the woods just yet. In addition to ACEs and PCEs, Bethell et al. (2019) included a measure of Adult- $\underline{R}$ eported $\underline{\text { Social }}$ and Emotional Support-ARSES. Honestly, I feel like that just sums up the whole matter right there.

The final entry in this section will be all too real for many of you. In the summer of 2009, as I was about to begin my new position as an Assistant Professor, I had a critically important decision to make: what clever acronym would I use for the name of my research lab? I wrote out of all of the key words and phrases associated with my research program and rearranged them until I found the answer: The Narrative, Identity, Culture, and Education Lab. The NICE Lab. It was perfect, as it captured the major aspects of my research and also fit with my desire to create a more welcoming and comforting environment for students. It also fit well in my department, because my colleague Steve Engel had recently set up his EVIL lab (Engel Vision and Imaging Laboratory) and then Shmuel Lissek joined a year later with the ANGST lab (Anxiety Neuroscience Grounded in cross-Species Translation). We are all very cute and fun.

Fast forward to 11 years later, and now I am questioning the name of my lab. It is fine, but does not fully capture the nature of my current or anticipated future work. I have thought about changing it, but current and past students-graduate and undergraduate-have a strong allegiance to it. I am not sure what I will do, but I feel like the lab name is not properly conveying what we are all about, and is misrepresenting our work to prospective students. Those of you who will soon be setting up a lab (and I know many of you are, given all of the twitter polls about which name to choose) can consider this a cautionary tale: Name your lab something reasonably generic so that you can maintain flexibility. Your research focus will almost certainly change. And besides, does the name of your lab really matter anyway?

WEIRD, ACEs, NICE-all seemingly innocuous and useful at the time, but they have downstream implications that shape conceptualization, measurement, and practice. Should acronyms have such power?

\section{Acronyms Can Eat Themselves over Time}

This section focuses on how acronyms that were developed for a specific purpose can, over time, be considered non-inclusive. With enough motivation among the plaintiffs, the original acronym can be expanded, often resulting in the acronym no longer being efficient nor consistent with the original meaning. I provide three very different examples of this.

The acronym STEM-science, technology, engineering, and mathematics-has had an interesting journey. Despite working in this area, I did not know until I just looked it up that the acronym was previously SMET, which is not the most pleasant word. It was not until 2001 that Judith Ramaley, a biologist at the National Science Foundation, made the change to STEM 
(Hallinen, 2015). Not only is it smoother on the tongue, but STEM connotes something important, fundamental, the stem of all other things. It was intended to bring together disciplines that use broadly common methods to address overlapping questions. Indeed, it has been a very successful acronym.

But, alas, it could not remain. The STEM acronym was used as a way to promote education focused on those fields and to lobby for funding. People in other fields felt that there was too much focus on STEM, and that STEM fields should be thought of in relation to, not as separate from, others. Thus came STEAM-inserting "Arts" in the middle, proposed by Georgette Yakman (https://steamedu.com/). STEAM focuses on a more integrative, holistic approach to learning that does not treat art and science as in opposition. You might think that is reasonable, but you also likely forgot that we are currently dealing with the absurd. Accordingly, the expansion has not stopped there. You can now find references to STEAMM, with a second M appended at the end, but that second $M$ could refer to Medicine (Blockley, 2019), Mindfulness (https://www.fullsteammahead.org/what-is-steamm-.html) or Ministry (https://lincolnchristianschool.com/arts/steamm-lab), or you can go into an entirely different direction and maybe STEAMM stands for $\underline{\text { S}}$-state Transition Eigenvalues of $\underline{\text { Asymmetric }} \underline{\text { Markov }}$ Models (Vinyard et al., 2013), or perhaps something else entirely. You can decide! But we are still not done, as the acronym has made the full move to initialism with STEAMM+D (Diamond, 2019)-here the final M stands for medicine and the D for design. I think it is safe to say that none of this is useful.

Here is one that is currently being discussed quite heavily in July 2020: BIPOC, which stands for Black, Indigenous, and People of Color (and it is an acronym, pronounced "byepock'). Whereas STEM to STEAMM+D represents a move from acronym to initialism, BIPOC moved in the other direction. The root initialism is POC, for People of Color. The term was created to foster solidarity and bring attention to some of the commonalities shared by the nonWhite residents of the United States. It was not intended to suggest that all POC are the same, have the same experiences, or anything of that nature. It was really a political move, much like other pan-ethnic labels used in the U.S. such as Asian American (Lee, 2015). Some years ago I started seeing IPOC, Indigenous Peoples and People of Color (sometimes IPPOC to include both Ps in the acronym; pronounced "eye-pock"). My three minute Google search did not turn up much about the history of this change, but my understanding of the motivation was that Indigenous peoples in the U.S. are often erased and made invisible in broader discussions of race, and thus there was a need to specifically bring attention to Indigenous peoples when discussing People of Color as a collective.

In just the past few months, we have seen huge increase in the use of BIPOC. Again, how this started is a little hazy (Garcia, 2020), but the thrust of it is that Black Americans, in additional to Indigenous peoples, have such a unique racialized experience that they should be specified individually so as to not lead to beliefs of sameness of equivalence with other POC. So, essentially the same general reason as for the use of IPOC. The term has clearly taken off in the context of George Floyd's murder by the Minneapolis police and the ensuing political action. Now I see it regularly rolling off the tongue of people who never talked about race before, acting like this is a term we have all known and understood for years. As nicely reported by Constance Grady (2020) in Vox, there is some confusion and mixed feelings about it use. There is a very

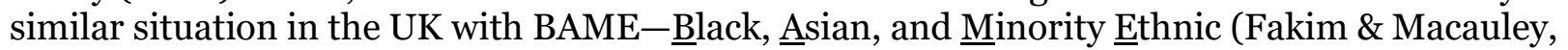
2020).

But lest you forget, we are in the land of the absurd. Already we see the modification from POC to BIPOC-while certainly understandable and well-justified-betray the intention of 
the original term, to highlight a shared struggle. Not that everyone who is part of that category is the same or has the same experiences, but that there is political value is recognizing and promoting the commonalities that are there. It may not be long before we see BILPOC to ensure we recognize the experiences of Latinos in the U.S. and then perhaps BILAPOC to include Asian Americans. If only we could come up with something shorter that would include everyone. And in case you do not think any of this is absurd enough, I actually saw reference to NBPOC-nonBlack People of Color (Smith, 2017). Perhaps we should just say exactly who we mean when we are talking about groups of people rather than relying on cryptic acronyms. ${ }^{1}$

Phew, are we still going? One more, this time for the open science crowd. One of the core problems in how psychologists write up their results for publication is known as HARKingHypothesizing After the Results are Known(ing), discussed by Kerr way back in $1998^{2}$. As the name implies, HARKing refers to the practice of obtaining some set of results and acting as though they had been hypothesized all along. Literally creating hypotheses after conducting a study and analyzing the data.

That right there is absurd enough. But if there is one thing we have learned though the last decade of scientific reform, it's that psychologists can always take their absurdity to new levels. In an attempt to bring nuance to our understanding of HARKing, Rubin (2017) argued that the practice can be broken down into three types CHARKing (Constructing Hypotheses after the Results are Known), RHARKing (Retrieving Hypotheses after the Results are Known), and SHARKing (Suppressing Hypotheses after the Results are Known), and that the three types vary in their ethical implications. Hollenbeck and Wright (2017) proposed an entirely different meaning for SHARKing (Secretly Hypothesizing after the Results Are Known) that is essentially the same as the original HARKing, and distinguished it from THARKing (Transparently Hypothesizing after the Results Are Known). If you are confused about what THARKing means, they further elaborate, "We define Tharking as "clearly and transparently presenting new hypotheses that were derived from post hoc results in the Discussion section of an article." (p. 11). Most of us know this as simply doing science, and it really has no business being associated with the nefarious practice of HARKing (which also does not need to be renamed as CHARKing or SHARKing). Oh, and be sure not to confuse THARKing with TARKing-Theorizing after Results are Known (Vancouver, 2018). I know, I know, absurd.

\section{Coda: Are Acronyms Really That Bad?}

Yes. I'm sure some of you readers could write something similar using an entirely different set of acronyms. These are just the ones that I come across in my small slice of scientific practice. There can be some value in using acronyms, and if you are interested in learning about those benefits and some best practices, then you should read Lang (2019).

Oh, and I know what you are thinking: acronyms help conserve words when writing, which is necessary to meet stringent word counts imposed by journals. If this is your major argument for maintaining acronyms in your papers, then you need to take a cold hard look at your approach to writing.

\footnotetext{
${ }^{1}$ Look, my research and teaching focuses on culture/race/ethnicity, so I get the complexities around these issues. We should obviously avoid clearly offensive terms, and words matter, but getting into a woke-a-thon about terminology and running a marathon on the euphemism treadmill is really not productive.

${ }^{2}$ I will submit that HARKing is a useful acronym, in part because it is itself referring to something absurd. There is a satisfying irony to it. What followed, however...
} 


\section{References}

Anda, R. F., Porter, L. E., \& Brown, D. W. (2020). Inside the Adverse Childhood Experience Score: Strengths, Limitations, and Misapplications. American Journal of Preventive Medicine, $O(0)$. https://doi.org/10.1016/j.amepre.2020.01.009

Bethell, C., Jones, J., Gombojav, N., Linkenbach, J., \& Sege, R. (2019). Positive Childhood Experiences and Adult Mental and Relational Health in a Statewide Sample: Associations Across Adverse Childhood Experiences Levels. JAMA Pediatrics, 173(11), e193007e193007. https://doi.org/10.1001/jamapediatrics.2019.3007

Blockley, D. (2019). What Can We Learn About STEAM from Bridges? In A. de la Garza \& C. Travis (Eds.), The STEAM Revolution: Transdisciplinary Approaches to Science, Technology, Engineering, Arts, Humanities and Mathematics (pp. 155-167). Springer International Publishing. https://doi.org/10.1007/978-3-319-89818-6 11

Brumback, R. A. (2009). ABRV (or Abbrevobabble Revisited). Journal of Child Neurology, 24(12), 1477-1479. https://doi.org/10.1177/0883073809340922

Cronholm, P. F., Forke, C. M., Wade, R., Bair-Merritt, M. H., Davis, M., Harkins-Schwarz, M., Pachter, L. M., \& Fein, J. A. (2015). Adverse Childhood Experiences: Expanding the Concept of Adversity. American Journal of Preventive Medicine, 49(3), 354-361. https://doi.org/10.1016/j.amepre.2015.02.001

Diamond, S. (2019). Addressing the imagination gap through STEAMM+D and indigenous knowledge. Proceedings of the National Academy of Sciences, 116(6), 1851-1856. https://doi.org/10.1073/pnas.1808679115

Fakim, N., \& Macaulay, C. (2020, June 30). “Don't call me BAME.” BBC News. https://www.bbc.com/news/uk-5.3194376

Felitti, V. J., Anda, R. F., Nordenberg, D., Williamson, D. F., Spitz, A. M., Edwards, V., Koss, M. P., \& Marks, J. S. (1998). Relationship of Childhood Abuse and Household Dysfunction to Many of the Leading Causes of Death in Adults. American Journal of Preventive Medicine, 14(4), 245-258. https://doi.org/10.1016/So749-3797(98)00017-8

Gaertner, L., Sedikides, C., Cai, H., \& Brown, J. D. (2010). It's not WEIRD, it's WRONG: When Researchers Overlook uNderlying Genotypes, they will not detect universal processes. Behavioral and Brain Sciences, 33(2-3), 93-94.

Garcia, S. E. (2020, June 17). Where Did BIPOC Come From? The New York Times. https://www.nytimes.com/article/what-is-bipoc.html

Hales, A. H., Williams, K. D., \& Rector, and J. (2017). Alienating the Audience: How Abbreviations Hamper Scientific Communication. APS Observer, 3O(2). https://www.psychologicalscience.org/observer/alienating-the-audience-howabbreviations-hamper-scientific-communication

Harden, P. (2018, October 27). Heredity is only half the story. The Spectator. https://www.spectator.co.uk/2018/10/heredity-is-only-half-the-story/

Henrich, J., Heine, S. J., \& Norenzayan, A. (2010). The weirdest people in the world? Behavioral and Brain Sciences, 33(2-3), 61-83. https://doi.org/10.1017/S0140525X0999152X

Hollenbeck, J. R., \& Wright, P. M. (2017). Harking, Sharking, and Tharking: Making the Case for Post Hoc Analysis of Scientific Data. Journal of Management, 43(1), 5-18. https://doi.org/10.1177/0149206316679487

Kushlan, J. A. (1995). Use and Abuse of Abbreviations in Technical Communication. Journal of Child Neurology, 10(1), 1-3. https://doi.org/10.1177/088307389501000101

Lang, T. (2019). The long and the short of abbreviations. European Science Editing, 45(1). https://doi.org/10.20316/ESE.2019.45.18018

Lee, E. (2015). The Making of Asian America: A History. Simon and Schuster. 
Masten, A. S. (2007). Resilience in developing systems: Progress and promise as the fourth wave rises. Development and Psychopathology, 19(3), 921-930. https://doi.org/10.1017/So954579407000442

Muthukrishna, M., Bell, A. V., Henrich, J., Curtin, C. M., Gedranovich, A., McInerney, J., \& Thue, B. (2020). Beyond Western, Educated, Industrial, Rich, and Democratic (WEIRD) Psychology: Measuring and Mapping Scales of Cultural and Psychological Distance. Psychological Science, 31(6), 678-701. https://doi.org/10.1177/0956797620916782

Narayan, A. J., Rivera, L. M., Bernstein, R. E., Harris, W. W., \& Lieberman, A. F. (2018). Positive childhood experiences predict less psychopathology and stress in pregnant women with childhood adversity: A pilot study of the benevolent childhood experiences (BCEs) scale. Child Abuse \& Neglect, 78, 19-30. https://doi.org/10.1016/j.chiabu.2017.09.022

Negriff, S. (2020). ACEs are not equal: Examining the relative impact of household dysfunction versus childhood maltreatment on mental health in adolescence. Social Science \& Medicine, 245, 112696. https://doi.org/10.1016/j.socscimed.2019.112696

Rubin, M. (2017). When does HARKing hurt? Identifying when different types of undisclosed post hoc hypothesizing harm scientific progress. Review of General Psychology, 21(4), 308-320. https://doi.org/10.1037/gprooo0128

Smith, S. D. (2017, March 6). Non-Black People Of Color Perpetuate Anti-Blackness Too. HuffPost. https://www.huffpost.com/entry/non-black-people-of-color-are-not-exemptfrom-being b 58 bdb5dbe4boec3d5a6ba143

STEM | Description, Development, \& Facts. (n.d.). Encyclopedia Britannica. Retrieved July 2, 2020, from https://www.britannica.com/topic/STEM-education

Syed, M., \& Kathawalla, U. K. (2020). Cultural psychology, diversity, and representation in open science. PsyArXiv. https://psyarxiv.com/t7hp2/

Vancouver, J. B. (2018). In Defense of HARKing. Industrial and Organizational Psychology, 11(1), 73-80. https://doi.org/10.1017/iop.2017.89

Vinyard, D. J., Zachary, C. E., Ananyev, G., \& Dismukes, G. C. (2013). Thermodynamically accurate modeling of the catalytic cycle of photosynthetic oxygen evolution: A mathematical solution to asymmetric Markov chains. Biochimica et Biophysica Acta (BBA) Bioenergetics, 1827(7), 861-868. https://doi.org/10.1016/j.bbabio.2013.04.008 